\title{
Boas Práticas em Pesquisa e a prevenção da má conduta acadêmica
}

Nas últimas décadas, temos observado uma crescente inquietação com a má conduta acadêmica (academic misconducting) e com o aumento da ocorrência de fraudes nas atividades de pesquisa. Atualmente, este tema representa um desafio permanente para a equipe editorial de qualquer revista acadêmica, tanto é que muitas delas passaram inclusive a adotar mecanismos de prevenção e proteção contra fraudes, com uso intensivo de tecnologias de informação. $\mathrm{O}$ assunto também ganhou relevância em diversas instituiçóes ligadas à pesquisa propriamente acadêmica, como universidades, indexadores de periódicos, bases de dados e agências de fomento. Estas instituiçôes vêm reforçando a importância da disseminação de Boas Práticas em Pesquisa e adotando mecanismos que visam desestimular as práticas de má conduta.

O crescimento de práticas de fraude e má conduta acadêmica é normalmente associado com a elevação das pressôes por publicação, em sua maioria vinculadas à progressão da carreira acadêmica e ao acesso a fundos de financiamento à pesquisa (BIAGIOLI et al., 2019). O lema "publicar ou perecer" ("publish or perish") resume bem as pressóes crescentes por publicaçôes no meio científico. A preocupação com a integridade acadêmica, porém, não é recente. Já no início da década de 1970, os estudos do sociólogo americano Robert Merton apontavam para o alto valor atribuído à originalidade dos trabalhos acadêmicos e para a reputação dos pesquisadores, associando esses à dificuldade de produzir pesquisa original e de elevado impacto (MERTON, 1973). Mais recentemente, esse tema ganhou novos contornos e novas características, uma vez que muitas instituiçóes em diversos países 
passaram a conferir crescente importância aos indicadores de impacto, o que elevou a pressão pela publicação e fez surgir novas práticas, muitas antiéticas ou fraudulentas, que não se limitam à produção de publicaçóes, mas visam melhorar a avaliação de sua importância ou impacto (BIAGIOLI; LIPPMAN, 2020).

A má conduta acadêmica, por sua vez, é definida como a fabricação, a falsificação ou o plágio ao propor realizar ou revisar pesquisas acadêmicas, ou ao relatar resultados de pesquisas. Esta definição não inclui erros honestos, diferenças de opinião ou ainda disputas de autoria, a menos que envolvam plágio (US Office of Science and Technology Policy. Federal Research Misconduct Policy, 2000).

A fabricação consiste em inventar dados, evidências materiais ou resultados e registrá-los ou relatá-los como se fossem verdadeiros. Ela ocorre, portanto, ainda durante o processo de pesquisa. Alguns casos recentes de fabricação de dados e resultados de pesquisa receberam grande destaque tanto nos meios acadêmicos, como nos não acadêmicos. Muito embora esses casos sejam graves e em certo sentido trágicos, eles parecem ser resultado de comportamentos individuais inadequados e, em muitas situações, podem ser associados com a crescente "divisão do trabalho" na pesquisa científica (WALSH, LEE; TANG, 2019). Em muitos desses casos, alguns dos coautores de trabalhos acusados de fabricação de resultados relataram desconhecer a origem completa dos dados que sustentavam a argumentação apresentada, e apontaram que foram responsáveis por apenas uma parcela, muitas vezes pequena, do trabalho publicado. A maior ocorrência de colaboraçóes científicas a elevadas distâncias geográficas, associadas às maiores possibilidades de comunicação remota, também parece ter estimulado o surgimento de casos de fabricação de resultados, dada a maior dificuldade de supervisão mútua dos trabalhos dos inúmeros pesquisadores envolvidos em diversas localidades (BERGGREN; KARABAG, 2019).

Já a falsificação consiste em alterar materiais, equipamentos ou processos de pesquisa, ou alterar ou omitir dados ou resultados de forma que o registro da pesquisa não reflita com precisão os seus resultados. A falsificação representa outra grave má conduta acadêmica. $\mathrm{O}$ crescimento no período recente das práticas de falsificação de dados e resultados de pesquisa acadêmica é muitas vezes associado com o 
aumento da disponibilidade de tecnologias da informação (BIAGIOLI et al., 2019). Práticas como a manipulação de figuras, a mineração seletiva de dados e a cópia integral de textos de outros autores, tarefas que antes precisavam ser feitas manualmente, foram imensamente facilitadas pelo uso de ferramentas de software (BIAGIOLI et al., 2019). Nos dias de hoje, o uso de ferramentas digitais simples e baratas permitem, sem grandes dificuldades operacionais, a reciclagem e a manipulação de textos, de dados, a alteração e a falsificação de imagens, e até mesmo a deturpaçáo de resultados. Nesse sentido, se no passado a fraude acadêmica era sobretudo artesanal, as novas ferramentas digitais abrem à falsificação amplas possibilidades que vão desde a elevação da velocidade das fraudes, até sua automatização em escala quase industrial (BIAGIOLI, 2019). Como resposta, a comunidade acadêmica tem procurado adotar mecanismos, como plataformas de verificação de similaridade de artigos e submissóes, a exemplo do TurnitIn, que indica possíveis incidências de plágio, a Licença a Licença Creative Commons e as Políticas Institucionais de Pesquisa, que indicam como os conteúdos podem ser compartilhados e disseminados, de modo a respeitar as Boas Práticas em Pesquisa Acadêmica.

Em muitos casos, o tema da falsificação tem levado à discussão sobre a ética na pesquisa acadêmica, uma vez que parece ser bastante tênue a linha entre o comportamento aceitável e inaceitável dos pesquisadores. Por exemplo, práticas como o relato seletivo dos resultados ou o corte de valores discrepantes mostram-se muito comuns, e são aceitas por parcela não desprezível de pesquisadores acadêmicos de diversas áreas. Alguns exemplos mostram que pesquisadores, tirando proveito de seus "graus de liberdade", se envolvem em possíveis práticas predatórias, que ajudam a fortalecer um resultado e, dessa forma, aumentam a sua importância e potencializam o seu impacto. Em casos como estes, há controvérsias importantes sobre o comportamento dos pesquisadores, uma vez que podem representar formas de má conduta acadêmica (BIAGIOLI et al., 2019). Alguns exemplos de prática bastante comuns na área de Ciências Sociais Aplicadas podem ser citados:

1. Um pesquisador poderia ter duas ou mais medidas da variável dependente de seu modelo empírico e relatar apenas aquela que melhor "funcionou" - ou simplesmente "funcionou"; 
2. Um pesquisador poderia coletar os dados e testar os efeitos significativos e, se eles náo forem encontrados, aumentar o tamanho da amostra e testar novamente, parando quando houver "dados suficientes para demonstrar o efeito";

3. Um pesquisador também poderia incluir ou descartar variáveis de controle, mantendo no modelo empírico somente aquelas que tornam o efeito desejável mais significativo;

4. Um pesquisador também pode fazer escolhas sobre a inclusão e sobre a exclusão de certos termos de interação.

Em casos como os acima relatados, verifica-se que é de fato bastante tênue a linha entre comportamento aceitável e inaceitável. Por isso, é importante manter a maior transparência possível na realização da pesquisa, o que envolve inclusive a disponibilização dos dados e informaçóes, quantitativas e qualitativas, em bases ou repositórios de dados. Isso permite que outros pesquisadores realizem o mesmo experimento, ou um experimento semelhante, e confirmem, ou não, os resultados encontrados. É papel das instituiçôes de pesquisa, das agências de fomento e das revistas acadêmicas estimular tanto a disponibilização dos dados utilizados quanto o debate sobre os métodos utilizados, os resultados alcançados e as suas implicaçóes.

A terceira prática de má conduta acadêmica é o plágio. Ele se configura como a prática de pegar o trabalho ou as ideias de outra pessoa e repassá-los como seus (VASCONCELOS et al., 2009). O plágio também é usualmente definido como a apropriação de ideias, processos, resultados ou palavras de outra(s) pessoa(s), sem dar a ela(s) o devido crédito. Trata-se de uma das formas mais antigas de má conduta acadêmica.

Do ponto de vista da difusão, disseminação e circulação de novos conhecimentos e resultados de pesquisa para a sociedade como um todo, o plágio poderia, inicialmente, até ser visto como benéfico, uma vez que aumentaria a disseminação e a circulação dos resultados da pesquisa científica. Porém, para a comunidade científica, ele se mostra como uma forma explícita de má conduta acadêmica, configurando-se como fraude, uma vez que o crédito por aquelas ideias foi desviado, privando o verdadeiro autor do reconhecimento que ele merece (VASCONCELOS et al., 2009). Como resultado, o pesquisador que 
realizou o plágio tem o seu currículo acadêmico supervalorizado a partir de trabalhos que não pesquisou ou escreveu, uma vez que trazem ideias, resultados ou textos que não foram de sua autoria. Por outro lado, o autor de fato daquele trabalho, ou daquelas ideias, pode ficar no esquecimento. Nesse caso, estas práticas de má conduta acadêmica conferem uma vantagem ilegal ao plagiador, podendo lhe dar vantagens em processos de avaliação, progressão ou em processos seletivos. No entanto, ao serem investigados e descobertos os plágios, essas posiçôes conquistadas ilegalmente podem ser desbancadas e o plagiador será certamente punido.

Além do plágio, outra forma de má conduta acadêmica é o autoplágio, que ocorre quando um pesquisador usa seu trabalho anteriormente publicado, ou mescla partes de trabalhos anteriores, para formular uma nova publicação. Ou seja, o autoplágio envolve a republicação de resultados científicos já divulgados pelo mesmo pesquisador, como se fossem novos, sem informar sobre a publicação prévia (SHINKAI, 2014). Nesse sentido, nos meios acadêmicos, essa prática normalmente é associada ao "requentamento" ou reciclagem de ideias "velhas" (BIAGIOLI et al., 2019). De certo modo, a palavra autoplágio é imprópria nos seus termos, uma vez que um autor não pode roubar um texto de si mesmo. Além disso, muitas vezes, pode ser difícil para um autor relatar adequadamente um estudo sem reutilizar ao menos partes de seus trabalhos prévios já publicados. Neste escopo, a linha entre a reciclagem aceitável de um texto já publicado e o autoplágio pode se mostrar confusa. Entretanto, a questão principal é o quâo original é a contribuição. Se o autor deseja retomar textos ou ideias já publicados, ele precisa fazer a devida citação de seu próprio trabalho. Recentemente um caso que ficou bastante famoso é de um proeminente pesquisador acadêmico holandês de economia regional, com elevadíssimo número de publicaçóes em sua carreira, que fora acusado de envolvimento em práticas de reciclagem de artigos em uma escala sem precedentes (HORBACH; HALFFMAN, 2019). Depois de vários processos e da investigação de mais de um comitê, esse pesquisador foi inocentado da maioria das acusaçóes, com a justificativa de que não houve a "intenção de enganar". De todo modo, alguns estudos mostram que, no geral, autores mais produtivos são mais propensos a 
reciclar textos de publicaçóes anteriores (HORBACH; HALFFMAN, 2019). Mesmo assim, ressalta-se que as práticas de autoplágio e de reciclagem de texto não são recomendadas em qualquer documento de Integridade e de Boas Práticas em Pesquisa.

Independente da forma que assume, o plágio detectado em trabalhos acadêmicos e publicações científicas implica violação moral e legal de direitos autorais e de propriedade intelectual e é passível de sançóes acadêmicas, financeiras e judiciais. No contexto da universidade, em casos extremos, o plagiador pode ser reprovado em um concurso e perder um posto ou título acadêmico. No caso das publicações científicas, a comprovação do plágio pode levar à retratação ou correção de um artigo publicado pelo pesquisador (SHINKAI, 2014). Normalmente, a identificação de um plágio ocorre por acaso, por uma reclamação de terceiros, ou ainda durante o processo de avaliação por pares. Recentemente, as universidades procuraram criar comitês internos para investigar e esclarecer casos de acusação de plágio e de má conduta acadêmica. Além disso, ao longo do tempo surgiram diversos softwares com ferramentas que atuam na detecção de plágio, que chegam a quantificar em porcentagem o texto duplicado. Mesmo com o desenvolvimento desses instrumentos, ainda não está claro para os membros dos comitês de ética e de integridade da pesquisa, nem para o conjunto da comunidade acadêmica, qual exato limite do índice de semelhança permite constituir plágio (SHINKAI, 2014).

Questóes como estas representam um desafio para as revistas acadêmicas. A adoção de Boas Práticas em Pesquisa pelos periódicos, e pela comunidade acadêmica como um todo, passa a ser fator fundamental para manter e aumentar a credibilidade da pesquisa e das publicaçốes, levando a ganhos de eficiência para todo o sistema acadêmico. A prevenção da má conduta tem como base a informação geral, a capacitaçáo docente e da equipe editorial, a formaçáo do aluno, especialmente os de pós-graduação, e o acompanhamento acadêmico contínuo (SHINKAI, 2014). Em geral, as universidades brasileiras, assim como os organismos de financiamento à pesquisa vêm, nos últimos anos, aprimorando o aparato institucional de Boas Práticas em Pesquisa, por meio da criação de políticas institucionais e pela delimitação dos papéis dos diferentes atores envolvidos no processo 
de geração e disseminação de novos conhecimentos científicos. Nesse sentido, é necessário promover esforços coordenados de combate ao plágio, à fraude e às demais formas de má conduta acadêmica, envolvendo as instituiçóes de pesquisa, as agências de fomento, as editorias das revistas acadêmicas e o público em geral.

\section{A RBI e as Boas Práticas em Pesquisa}

Desde sua fundação a Revista Brasileira de Inovação (RBI) preza pelo compromisso com a ciência e com as Boas Práticas científicas e editoriais. Tais diretrizes sempre pautaram a Política Editorial da revista. Neste ensejo, a RBI vem cada vez mais se alinhando a práticas que buscam reforçar a integridade da pesquisa em vários níveis, e na própria publicação acadêmica em si. O tema "estudos da inovação", central na revista, por sua natureza, constantemente nos convida a ter atenção a estas atualizaçóes, seja na pesquisa em termos gerais, seja no que se refere à publicaçáo, e mais especificamente à RBI. Neste sentido, ao longo de sua trajetória, a RBI vem frequentemente se atentando às recomendaçóes brasileiras e internacionais de Boas Práticas em Pesquisa, aplicando-as dentro da gestão e da equipe editorial e incentivando sua disseminação entre toda a comunidade científica da área de "estudos da inovação".

Seja pelos compromissos e por seus bons resultados, seja pelas relevantes pesquisas acadêmicas na área de "estudos da inovação" que ela publica, ao longo de seus dezenove anos de história, a RBI vem sendo cada vez mais reconhecida pela comunidade científica como um importante veículo de publicação acadêmica. $\mathrm{O}$ reflexo direto deste reconhecimento nos chega pelas prestigiadas submissóes que a revista segue recebendo, pelos acessos e citaçôes de suas publicaçôes, pelo apoio que recebe da comunidade e também por suas indexaçóes, que agora também incluem uma das mais importantes e prestigiadas bases indexadoras de publicaçóes acadêmicas, a Scientific Electronic Library Online ( $\underline{\text { ciELO)}}$.

Estas importantes conquistas nascem da soma de esforços de toda a comunidade, composta de autores comprometidos com o desenvolvimento de pesquisas na área de "estudos da inovação", de um 
corpo editorial dedicado à revista, das inestimáveis contribuiçôes dos revisores, do envolvimento de uma equipe editorial técnica especializada em publicaçóes científicas, de apoios e financiamentos expressivos. Dentre os constantes apoiadores da RBI está a Universidade Estadual de Campinas (Unicamp), e, em especial, o Departamento de Política Científica e Tecnológica (DPCT) do Instituto de Geociências (IG) da Unicamp, onde a revista está sediada. A revista figura ainda no Portal de Periódicos da Unicamp (PPEC), que concentra os periódicos científicos da universidade.

Tais esforços já haviam rendido à RBI indexaçóes na Web of Science (WoS) Emerging Sources Citation Index (ESCI), no Directory of Open Access Journals (DOAJ), no Latindex - Sistema Regional de Información en Línea para Revistas Científicas de América Latina, el Caribe, España y Portugal, no Portal de Periódicos-Capes, entre outros, aos quais agora a SciELO se soma.

Atenta aos critérios desses indexadores e portais e às recomendaçóes de instituições como a Fundação de Amparo à Pesquisa do Estado de Sáo Paulo (Fapesp), a Committee on Publication Ethics (COPE), a Committee on Publication Ethics (COPE), a American Educational Research Association_https://cdn.ymaws.com/wera.site-ym.com/ resource/resmgr/a general/aera.pdf), o Council of Science Editors (https://www.councilscienceeditors.org/resource-library/editorial-policies/white-paper-on-publication-ethics/) e o SciELO, a RBI vem frequentemente atualizando e aprimorando suas Boas Práticas editoriais e científicas e viabilizando a composição de uma publicação que cada vez mais se torna reconhecida dentro e fora do país.

Incentivando as Boas Práticas, a RBI procura promover na comunidade cada vez mais um senso de responsabilidade pela pesquisa acadêmica, produzida tanto no nível individual quanto no coletivo. Tais práticas intensificam a capacidade de validar pesquisas produzidas de forma ética, ampliam o acesso a artigos avaliados e reconhecidos por pares e, por conseguinte, o seu impacto. A publicação dos artigos com celeridade em formato online, com acesso aberto, gratuito e sem embargos, procura efetivar esta proposta, permitindo aos leitores conhecerem os resultados de pesquisa de forma mais ágil e ampliada. 
Neste escopo, a RBI realiza também, desde 2018, a validação de um Digital Object Identifier (DOI) para cada artigo publicado, identificando e facilitando seu acesso na internet. Desde 2019 todos os autores e coautores que assinam os artigos da RBI apresentam suas afiliaçôes institucionais, bem como seu número de cadastro no ORCID, um identificador digital global de pesquisadores acadêmicos. Em 2020, a RBI passou a ser publicada em fluxo contínuo, passando a preparar e publicar os artigos logo após sua aprovação por pares, o que vem conferindo mais agilidade à divulgação dos resultados de pesquisa publicados na revista. O periódico tem também publicado, para cada artigo, dados sobre a contribuição dos autores, a fonte de financiamento da pesquisa e a informação sobre conflito de interesse, todos declarados pelos autores e disponibilizados ao final de cada publicação.

No âmbito da proteção contra práticas de má conduta acadêmica, a revista adotou um mecanismo de deteç̧ão de similaridade para todas as submissóes recebidas, de modo a possibilitar a identificação de possíveis plágios e autoplágios por meio da plataforma TurnItin. Nesse sentido, a revista procura incentivar a boa conduta e a boa apresentação das pesquisas científicas e desestimular quaisquer práticas relativas a fabricação, falsificação, plágio e autoplágio de dados. Em consonância com as boas práticas, a revista ainda incentiva a disponibilização de dados e informaçôes em bases ou repositórios de dados científicos e se reserva a possibilidade de consultar os autores sobre os dados utilizados por eles para a realização das pesquisas que estão sendo divulgadas nos artigos publicados.

Com estes cuidados, a RBI se mostra atenta, procurando evitar as práticas de má conduta acadêmica, cujo crescimento, como já apontado, vem sendo tanto observado quanto investigado, divulgado e prevenido (BIAGIOLI et al., 2019; LINTON, 2014; SHINKAI, 2014; VASCONCELOS et al., 2009).

Com transparência, a RBI segue buscando excelência em suas publicaçôes, levando à comunidade os resultados de pesquisas acadêmicas na área de "estudos da inovação" e, ao mesmo tempo, informando e tornando ativas as Boas Práticas pertinentes à ciência de modo geral. Ao manter-se atualizada, a revista ratifica seu com- 
promisso em diversos níveis, buscando sempre confirmar a ética e o compromisso com a integridade da pesquisa, com a ciência e com a publicação, elementos que à Revista Brasileira de Inovação sempre se mostraram fundamentais.

\section{Referências bibliográficas}

AMERICAN EDUCATIONAL RESEARCH ASSOCIATION. Code of Ethics, 2011. Acesso em: 02 fev. 2021. Disponível em:

https://cdn.ymaws.com/wera.site-ym.com/resource/resmgr/a_general/aera.pdf.

BERGGREN, C.; KARABAG, S.F. Scientific misconduct at an elite medical institute: The role of competing institutional logics and fragmented control. Research Policy, v. 48, n. 2, p. 428-443, 2019. DOI:

https://doi.org/10.1016/j.respol.2018.03.020.

BIAGIOLI, M. Before and After Photoshop: Recursive Fraud in the Age of Digital Reproducibility. Angewandte Chemie International Edition, v. 58, n. 46, 2019.

BIAGIOLI, M.; LIPPMAN, A. Gaming the metrics: misconduct and manipulation in academic research. Cambridge, MA: MIT Press, 2020.

BIAGIOLI, M.; KENNEY, M.; MARTIN, B.; WALSH, J. Academic misconduct, misrepresentation and gaming: A reassessment. Research Policy, v. 48, n. 2, p. 401-413, 2019. https://doi.org/10.1016/ j.respol.2018.10.025.

COUNCIL OF SCIENCE EDITORS. Acesso em: 02 fev. 2021.

Disponível em: https://www.councilscienceeditors.org/.

COMITEE ON PUBLICATION ETHICS. Cooperation between research institutions and journals on research integrity cases: guidance from the Committee on Publication Ethics (COPE). Disponível em: https://

publicationethics.org/files/Research_institutions_guidelines_final_0_0.pdf. Acesso em: 10 jan. 2020.

DOAJ. Disponível em: https://doaj.org. Acesso em: 10 jan. 2020.

FUNDAÇÃO DE AMPARO À PESQUISA DO ESTADO DE SÃO

PAULO.Código de Boas Práticas Científicas. Disponível em:

https://fapesp.br/boaspraticas/FAPESP-

Codigo_de_Boas_Praticas_Cientificas_2014.pdf. Acesso em: 10 jan. 2020. 
HORBACH, S.S.; HALFFMAN, W.W. The extent and causes of academic text recycling or 'self-plagiarism'. Research Policy, v. 48, n. 2, p. 492-502, 2019. INSTITUTO DE GEOCIÊNCIAS DA UNICAMP. Periódicos do IG. Disponível em: https://portal.ige.unicamp.br/institucional/periodicos-do-ig. Acesso em: 10 jan. 2020.

LATINDEX. Directório. Disponível em:

https://www.latindex.org/latindex/ficha?folio=12904. Acesso em: 10 jan. 2020.

LINTON, J. Academic dishonesty primer: How to avoid it-Advice for authors. Technovation, v. 34, n. 1, p. 1-2, 2014. ISSN 0166-4972. https:// doi.org/10.1016/j.technovation.2013.11.002.

MERTON, R.K. The Sociology of Science: Theoretical and Empirical Investigations. Chicago: University of Chicago Press, 1973.

PORTAL DE PERIÓDICOS CAPES. Disponível em:

https://www-periodicos-capes-gov-br. Acesso em: 10 jan. 2020.

PORTAL DE PERIÓDICOS DA UNICAMP. Disponível em:

https://periodicos.sbu.unicamp.br/ojs/index.php/index/search/?query=revista +brasileira+de+inova\%C3\%A7\%C3\%A3o. Acesso em: 10 jan. 2020.

REVISTA BRASILEIRA DE INOVAÇÃO. Disponível em:

https://periodicos.sbu.unicamp.br/ojs/index.php/rbi/about. Acesso em: 10 jan. 2020.

SCIENTIFIC ELECTRONIC LIBRARY ONLINE. Guia de boas práticas para o fortalecimento da ética na publicaçáo científica. Disponível em:

http://old.scielo.org/local/File/Guia\%20de\%20Boas\%20Praticas\%20para\%20 o\%20Fortalecimento\%20da\%20Etica\%20na\%20Publicacao\%20Cientifica.pdf. Acesso em: 10 jan. 2020.

SCIENTIFIC ELECTRONIC LIBRARY ONLINE. Seleção de Periódicos. Disponível em: https://www.scielo.br/avaliacao/20200403_pt.htm. Acesso em: 10 jan. 2020.

SHINKAI, R.S.A. Originality and plagiarism: a question of authorship in the Academy. Rev. esc. enferm. USP, São Paulo, v. 48, n. 3, p. 388-393, 2014. DOI: https://doi.org/10.1590/S0080-623420140000300001.

VASCONCELOS, S.; LETA, J.; COSTA, L.; PINTO, A.; SORENSON, M.M. Discussing plagiarism in Latin American science. Brazilian researchers 
begin to address an ethical issue. EMBO Reports, v. 10, n. 7, p. 677-682, 2009. DOI: https://doi.org/10.1038/embor.2009.134.

WALSH, J.P.; LEE, Y.N.; TANG, L. Pathogenic organization in science: Division of labor and retractions. Research Policy, v. 48, n. 2, p. 444-461, 2019. DOI: https://doi.org/10.1016/j.respol.2018.09.004.

WEB OF SCIENCE. Master Journal List - Search Journals. Disponível em: https://mjl.clarivate.com/search-results. Acesso em: 10 jan. 2020.

Wilson Suzigan, editor (D)

Universidade Estadual de Campinas (Unicamp), Campinas, SP, Brasil.

E-mail: wsuzigan@unicamp.br

https://orcid.org/0000-0002-2193-4756

Renato Garcia, editor adjunto

Universidade Estadual de Campinas (Unicamp), Campinas, SP, Brasil.

E-mail: rcgarcia@unicamp.br

https://orcid.org/0000-0001-9739-1658

Tatiana Massaro, gerente editorial (2018-2019) ${ }^{1}$

Universidade Estadual de Campinas (Unicamp), Campinas, SP, Brasil.

E-mail: ttmassaro@gmail.com

https://orcid.org/0000-0002-9153-9938

SubMisSÃo: 26 DE JANEIRO DE 202 I AProvado: O9 DE ABRIL DE 202I

1 Tatiana Massaro atuou como gerente editorial na Revista Brasileira de Inovação entre 2018 e 2019. Atualmente, é doutoranda em Antropologia Social pela Unicamp.

\section{(c) (1)}

Este é um artigo publicado em acesso aberto (Open Access) sob a licença Creative Commons Attribution CC-BY, que permite uso, distribuição e reprodução em qualquer meio, sem restriçôes desde que o trabalho original seja corretamente citado. 